\title{
The Credit Rating of Selected Distance Education Study Material at the OUSL
}

\section{BUDDHI WEERASINGHE}

GAMINI S. ALGAMA

PADMIKA C. DE SILVA

This paper investigates the concept of credit rating in terms of the study time related to Distance Education courses and compares the courses at OUSL with the norms accepted at OUUK. It presents the variability of workload in courses of study at OUSL by converting the number of pages and hours spent on practical components into study hours. It then analyses student performances of different courses and seeks out whether seemingly compatible workloads produce better student performances. Undergraduate student responses obtained through questionnaires on selected aspects of study material such as the level of difficulty and the ability to complete the allowed upper limit of course credits per academic year are related to time spent on studies. These are then compared with responses of graduands. Based on these findings the paper investigates the question whether the credit rating assigned to OUSL courses reflect a need for re-assessment. 


\section{INTRODUCTION}

With nearly fifteen years of experience as the premier institute of distance education in the country, the Open University of Sri Lanka (OUSL), has embarked on restructuring its study programmes. Follow up studies on the compatibility of the 'workload' and the 'expected study time' for courses offered under this restructuring, would be beneficial to understand its effectiveness. The study presented here was a pioneering effort to investigate the workload of OUSL courses. This early study seems to have had several limitations. However, it has unveiled several interesting issues which are of relevance to similar studies being planned within the restructured programmes. These issues are therefore presented here to serve as a base-line for future studies.

Specifying the study time required to complete a distance education course has become common practice in defining 'workload' and 'credit rating'. The Open University of the United Kingdom. (OUUK), had based its calculations of study time required on the findings of the Hale Report (Chambers, 1994). Conventional university students in the UK. who study full-time, spend an average of 40 hours per week during term time. Based on this estimate Open University students, who are assumed to be part-time students were expected to work no more than 14 hours per week for 32 weeks. This however did not include tutorial sessions and preparation for examinations. A Bachelor's Degree at OUUK takes six years to complete on this basis. 
However as all teachers are aware, some students gain more knowledge in less time than others. Thus standards for achievement in any course must allow for varying rates of learning (Novak, 1984). Perhaps for this reason, time allocation for workloads tend to be based on estimates calculated for an 'average' student. Lockwood, Williams and Roberts (1988) presented 'study rates' for the U.K as follows:

An easy read $=100 \mathrm{wpm}$

A fairly straight forward text $=70 \mathrm{wpm}$

A dense/difficult text $=40 \mathrm{wpm}$

The rates given are rates of reading in relation to comprehension.

On this basis, taking 70 wpm for discursive text, one hour's reading has been calculated to be 45 pages at an average 100 words per page (Chambers, 1992).

Excessive workloads have been attributed to a reduction in the quality of learning (Chambers, 1992).

OUSL has based its workload for course material on the OUUK model and specifies one 'course credit' as the amount of material which requires 450 hours of study (at an average of 15 hours per week). These hours of study need to accommodate not only lesson material in print but also audio-visual material, reference material, assignments, practical components and project work where relevant:

'Rules of thumb' have set guidelines for the length of a lesson at OUSL. A lesson is expected to cover content equivalent to the quantum presented within a one hour lecture of conventional university teaching. As a part-time student, the OU student is expected to spend two hours on each such lesson. A lesson unit usually comprises 2500 to 3000 words (Samarawickrema, 1997) at an average of 300 words per page i.e. approximately 10 pages. which. is a lesser workload than that outlined for OUUK findings. 
As mentioned above, course credit is based on the upper limit of 450 hours. A one-credit course at OUSL therefore implies 450 hours of study, and credit rating of OUSL courses is based or estimates related to this "credit". A half-credit course therefore involves 225 hours of study, a one-third credit 150 hours and so on.

A student is allowed to offer courses which add up to a maximum of two credits per academic year ie. 900 hours of study.

A student needs to register for a minimum of a 'half' credit per academic year if he desires to follow a study programme.

OUSL offers several levels of study as follows.

\section{Foundation -}

This is of two years duration or two levels of study denoted as Level 1 (Year 1) and Level 2 (Year 2)

\section{Undergraduate_-}

Undergraduate studies require three or four years of study denoted as Level 3 (Year1), Level 4 (Year2), Level 5 (Year 3) and Level 6 (Year 4)

The 'course credits' required for the award of a Bachelor's Degree in the three Faculties at OUSL at the time this study was conducted, are given below.

$\begin{array}{ll}\text { Bachelor of Technology (B.Tech) } & 8 \\ \text { Bachelor of Law (LL.B.) } & 8 \\ \text { Bachelor of Science (B.Sc) } & 4 \\ \text { (plus eligibility in 2 additional credits) } & \end{array}$

The requirement for the B.Sc. has been changed recently to six credits. Eligibility here refers to a qualifying standard a student must achieve for each course of study to enable him to sit the final examination. Eligibility is computed from scores obtained on work assigned for continuous assessment. 
Foundation courses are offered by students without the pre-requisite qualifications to enter an undergraduate programme. The Bachelor of Science and Bachelor of Technology programmes offer foundation courses. Most courses in these two programmes offer laboratory work. Some include field work.

An OUSL Diploma programme requires two 'credits' per year for completion. Those who complete Levels 3 and 4 in the B.Tech programme are offered a Diploma in Technology on successful completion.

This study has attempted to disclose the possible connections between workload and student performances at examinations. Here, another 'Rule of thumb' has been used to look at performances viz: that norm referenced group testing to grade performance of a student population must reflect a normal distribution or bell shaped curve.

\section{METHODOLOGY}

\section{Workload}

All courses in the three faculties were looked at in terms of the

- number of pages in print material

- number of hours spent on laboratory work (where relevant)

The number of pages were converted to study hours on the basis that 10 pages of print material needed 2 hours of study. Courses that required additional hours of practical work in a laboratory were tallied taking this requirement into consideration. In order to compare variability between workload of different courses, the study hours so obtained were converted to 'one credit equivalents'.

Results are presented as a 'high/low' chart (see Figure 1), for different levels of study, faculty wise. 


\section{Student performance}

Performances for courses offered at different levels of study for the selected study programmes were limited to the academic year 1991/92. At OUSL, performance grades are denoted as follows:

$\mathrm{PA}=$ Pass with distinction

$\mathrm{PB}=$ Pass with credit

$$
\begin{aligned}
& \mathrm{PC}=\text { Pass } \\
& \mathrm{PD}=\text { Weak Pass } \\
& \mathrm{RE}=\text { Re-sit }
\end{aligned}
$$

Percentages of each grade given per course were plotted as histograms. The histograms represent the total population of students registered for the course. The affinity of the histogram to a bell shape by appearance has been noted.

\section{Student responses}

These were obtained using questionnaires . The responses reflect student perception of workload of courses selected for the study. As, during the pilot study, it was found that the rate of responses by post was low, the questionnaires were distributed and collected from undergraduates at day schools or laboratory sessions.

In the analysis, responses on ability to carry two credits each academic year were matched with characteristics such as gender, age, employment and pattern of study, to find out existing relationships.

\section{Graduand responses}

Graduand responses were collected during the registration for the OUSL Alumni Association conducted prior to the annual convocation. Questionnaires for graduands focused on student ability to successfully complete 2 credits within one academic year. However, it must be noted that at the time of sampling, only graduands for the B.Sc. and LL.B. programmes were available. The responses have been tallieu anu presented as perceñages. 


\section{FINDINGS}

\section{Sample profiles}

Table 1 presents the profile for undergraduates in the selected programmes.

Table 1 - Undergraduate Profile

\begin{tabular}{|l|l|l|l|}
\hline Programme & $\begin{array}{l}\text { Number } \\
\text { of } \\
\text { studenats }\end{array}$ & $\begin{array}{l}\text { Gender } \\
\text { (\% male) }\end{array}$ & $\begin{array}{l}\text { \% below 35 } \\
\text { years }\end{array}$ \\
\hline B. Sc & 121 & 42 & 80 \\
\hline B. Tech & 15 & 98 & 96 \\
\hline $\begin{array}{l}\text { Diploma in } \\
\text { Technology }\end{array}$ & 43 & 82 & 100 \\
\hline LL.B. & 151 & 65 & 62 \\
\hline
\end{tabular}

Due to the relatively small sample sizes, the breakdown into age groups was limited to two groups viz: below 35 years and above 35 years.

The graduand profile is given in Table 2 .

Table 2 - Graduand Profile

\begin{tabular}{|l|l|l|l|}
\hline Programme & $\begin{array}{l}\text { Number of } \\
\text { Graduates }\end{array}$ & $\begin{array}{l}\text { Gender } \\
(\% \\
\text { male })\end{array}$ & $\begin{array}{l}\text { \% below } \\
\text { 35 years }\end{array}$ \\
\hline B.Sc. & 44 & 46 & 76 \\
\hline LL.B. & 42 & 52 & 64 \\
\hline
\end{tabular}




\section{Variation of course workload based on 'one credit equivalent'}

Figure 1 represents the high-low range of workloads for courses in the selected programmes of study.

The variability of workload in different courses becomes apparent from Figure 1.

Figure 1 - Variation of Workload

(Based on one credit equivalents)

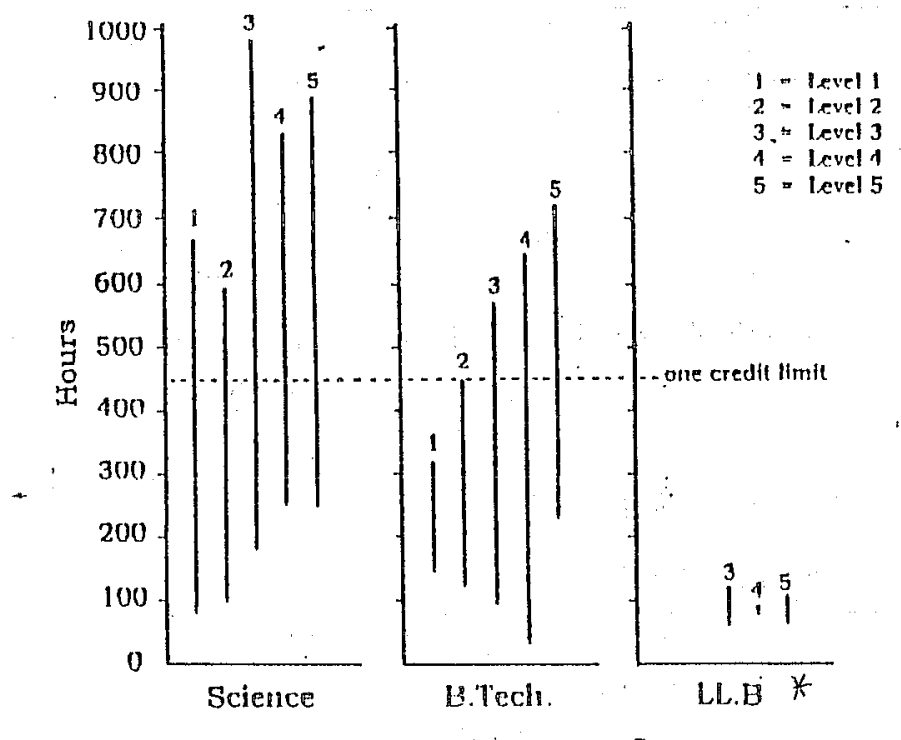

*NB: For the LLB, components such as reference and case studies from Law Reports were not included.

Although only the extreme limits are indicated, the study revealed that the majority of courses in the Science as well as the Technology programme carry a workload far above the expected 450 hours per credit. 
Courses in the Law programme on the other hand, appear to carry a workload much below than expected. It must however be noted that in the case of Law, only, time required for reading print material was computed. The study did not take into account the time required for reading reference material, reports of cases etc. all of which are intrinsic elements of study in the Law programme.

\section{Student performance}

A majority of the courses at all study levels of the B.Sc, B.Tech, and Diploma in Technology programmes showed a 'skewed' distribution with very high percentages of 'weak pass (PD)' and 're-sit (RE)'. Very few exceptions to this trend were noted. Figure 2 presents distributions for a sample of a variety of courses with differing workloads.

Figure 2 - Trends in the Distribution of Grades (B.Sc \&

\section{B.Tech)}

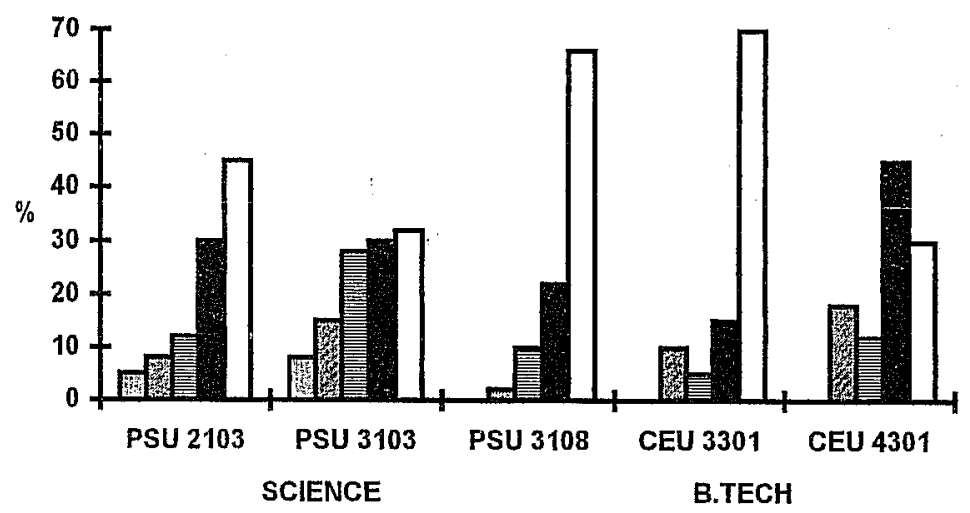


Respective workloads (as one credit equivalents) for these courses are indicated below.

$\begin{array}{ll}\text { Course code } & \text { Workload (hours) } \\ \text { PSU 2103 } & 96 \\ \text { PSU 3103 } & 924 \\ \text { PSU 3108 } & 240 \\ \text { CEU 3301 } & 728 \\ \text { CEU4301 } & 255\end{array}$

These findings seem to indicate that there is no correlation between workload and performance. A course which has a workload as low as 96 hours does not seem to have resulted in positive performances, while performance in PSU 3108 which has a workload of 240 hours seems to be similar to that of CEU 3301 which has a workload of 728 hours.

Levels 3 and 4 of the LL.B. programme exhibited the same trend in performance as for B.Sc. and B. Tech, in that the bell shape was skewed towards 're-sit' grade. However, results of levels 5 and 6 show a shift towards the bell shape. The 'weak pass' percentages are greater than that for 're-sit' students. Levelwise distributions are therefore represented for this study programme. Figure 3 presents the distribution of grades for the LL.B. courses. 
Figure 3 - Grade Distribution for courses in different levels of study (LL.B.)

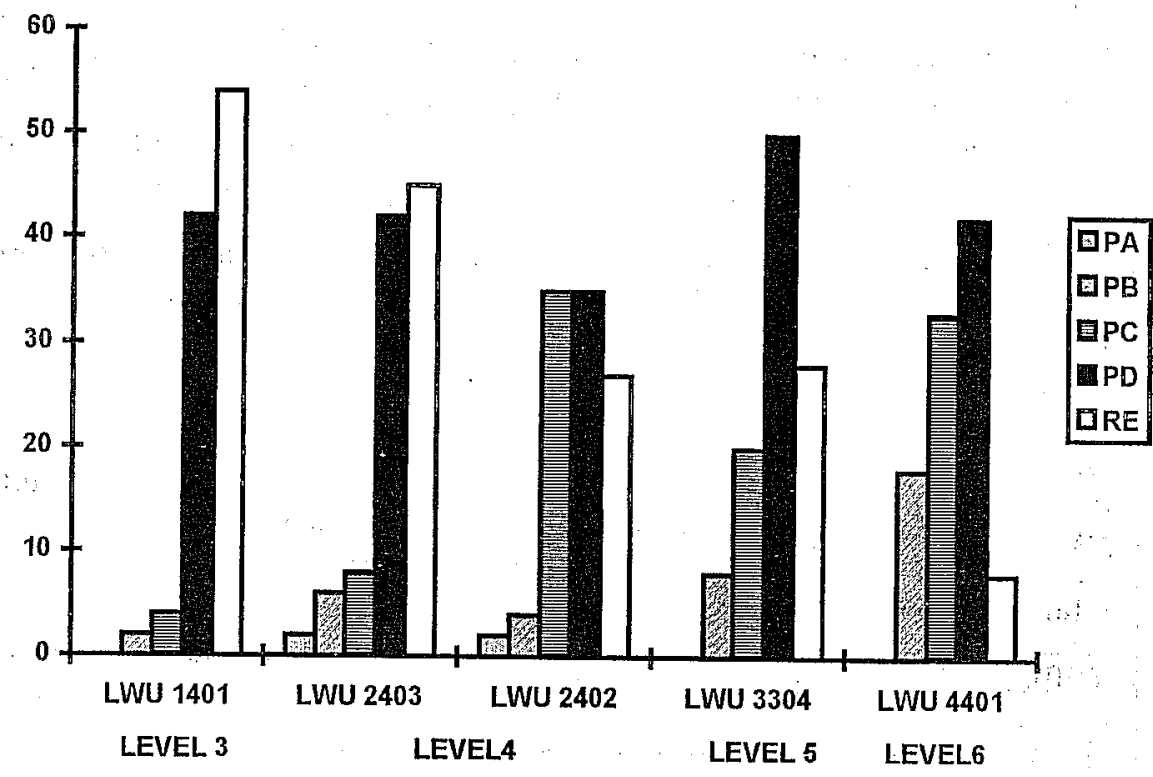

\section{Undergraduate responses on ability to carry two credits}

Student empathy on the ability to carry two credits, each academic year ,was surveyed as four categories of responses viz: 'very easy', 'easy', 'manageable' and 'difficult'. These responses were then analysed as follows.

\section{Responses Vs Employment}

The fact whether students were employed or not did not seem to have any bearing on responses.

\section{Responses Vs Gender}

A genderwise variation of responses was seen with the B.Sc and B.Tech. students for 'very easy and 'easy' response categories. Cumulative percentage for these two response categories was $6 \%$ for females and $18 \%$ for males. 


\section{Respo踏es Vs Age}

No agewise variation was apparent with the students of the LL.B. programme.

Agewise variation for the B.Sc. and B. Tech. students showed similar trends and their cumulative percentages are given in Table 3 .

Table 3. Response categories agewise for B.Sc and B.Tech as percentages.

\begin{tabular}{|c|c|c|}
\hline $\begin{array}{l}\text { Response } \\
\text { category. }\end{array}$ & $\begin{array}{l}\text { \% below } 35 \\
\text { years }\end{array}$ & $\begin{array}{l}\% \text { above } 35 \\
\text { years } \\
\text { s. }\end{array}$ \\
\hline Very Easy & 雚 & $21:$ \\
\hline Easy & 7 & $37: \frac{1}{10}$ \\
\hline Manageable & $\begin{array}{lll}43 & 4 \\
\end{array}$ & 38 \\
\hline Difficult & 4511 & 4 \\
\hline Total & 100 & $100 \therefore \because$ \\
\hline
\end{tabular}

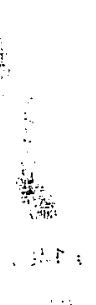

$96 \%$ of the older age group seemed to have found their course(s) of study manageable while only $55 \%$ of the younger age group found their study programmes 'easy' or 'manageable'.

It therefore appeared that older students in B.Sc. and B.Tech. programmes perceived it easier to carry a workload of two credits per academic year.

\section{Responses Vs Programme of study}

Analysis of responses programmewise showed clear differences between programmes. Percentages for different response categories programmewise are given in Table 4. 
Table 4. Response categories programmewise as percentages

\begin{tabular}{|l|l|l|l|l|}
\hline $\begin{array}{l}\text { Response } \\
\text { Category }\end{array}$ & $\begin{array}{l}\text { LU.B. } \\
\text { LL. }\end{array}$ & $\begin{array}{l}\text { B.Sc. } \\
\text { Very easy }\end{array}$ & $\begin{array}{l}\text { B.Tech. } \\
\text { Diploma } \\
\text { in Tech. }\end{array}$ \\
\hline Easy & 0 & 8 & 0 & 10 \\
\hline Manageable & 42 & 70 & 52 & 64 \\
\hline Difficult & 58 & 10 & 40 & 12 \\
\hline Total & 100 & 100 & 100 & 100 \\
\hline
\end{tabular}

None of the LL.B. students seemed to have found the programme 'easy' or 'very easy'. In fact $58 \%$ seemed to have found it difficult to carry two credits.

It appears that the LL.B. students perceived the workload of two credits per academic year to be more strenuous than students involved in other programmes of study. B.Tech students found the workload more difficult to carry than the Diploma students. A significant majority in the B.Sc. found the load manageable.

\section{Responses Vs Study pattern}

The responses for study pattern showed a strong relationship with those obtained on the ability to carry two credits within an academic year. Four study patterns were presented for student responses viz: Regular study, Study concentrated for continuous assessments, Study concentrated for Examination and Study at irregular intervals. Responses correlated to study patterns are given in Table 5. 
WEERASINGHE, ALGAMA \& DE SILVA

Table.5. Response categories study patternwise as percentages

\begin{tabular}{|l|l|l|l|l|}
\hline Study pattern & $\begin{array}{l}\text { Very } \\
\text { easy }\end{array}$ & Easy & Manageable & Difficult \\
\hline Regular study & 64 & 54 & 14 & 38 \\
\hline $\begin{array}{l}\text { For continuous } \\
\text { assessments }\end{array}$ & 20 & 16 & 80 & 15 \\
\hline $\begin{array}{l}\text { For } \\
\text { Examination }\end{array}$ & 14 & 6 & 10 & 5 \\
\hline Irregularly & 2 & 24 & 8 & 42 \\
\hline Total & 100 & 100 & 100 & 100 \\
\hline
\end{tabular}

A majority of the students who found carrying two credits 'very easy' or 'easy' studied regularly. Of those who responded with 'manageable', $80 \%$ concentrated on studying for continuous assessments. $42 \%$ of students who found it 'difficult'. to carry two credits, studied at irregular intervals. It is important to note that $38 \%$ (a sizeable percentage) of those who studied regularly found it difficult to complete their courses. This may indicate that the academic workload is heavy and difficult to cope with for a sizeable segment of the student population.

\section{Graduand responses}

The graduands were asked to indicate success in completing two credits at each study level within one academic year. Only graduates who read for the degrees of Bachelor of Science and Bachelor of Law were sampled (see Table 2). In the Bachelor of Science programme, $42 \%$ succeeded in carrying two credits at level 3, $12 \%$ at level 4 and $36 \%$ at level 5 .

In the Bachelor of Law programme, $80 \%$ managed to carry two credits at levels 3, 5 and 6 . At level 4, the completion of two credits remained at $62 \%$. 


\section{Discussion}

Chambers (1994) reviewing research conducted on study time observes that

"it is pointless to construct curricula and courses which require students to work for more than 40 hours per week, or the part time equivalent, whatever the type or level of study".

In the light of this comment, the picture presented of the workloads of the B.Sc. and B.Tech. programmes in 1992 is a matter of concern (see Figure 1). This overloading is further highlighted by the graphs in Figure 2. Here the curves are skewed not towards better performance but towards weaker grades and repeat performances. Skewed curves are acceptable in criterion referenced evaluation where a higher percentage of A or B grades may be seen (Novak, 1977). However, the shift observed in this study has been towards the 'weak pass' and 're-sit' categories. Furthermore, evaluation at the OUSL takes the form of traditional norm referenced testing. This study is incomplete because it cannot conclusively explain observed trends in performance.

The quality of instructional material, delivery mechanisms, student motivation, initial background knowledge, cognitive skills of the learner and many other possible reasons may be listed as contributing to poor student performance. Whether these contribute to poor performance during the earlier years where students adjust to a new mode of study through the distance mode is not known. This study seems to recognise workload as one possibility that contributes to observed performance. Future studies of this nature should address such issues related to performance where possible.

Increased workloads have been related to increased drop-out rates in open learning (Woodley and Parlett, 1983). This study had not investigated drop-out rates. However, performance in the LL.B. programme (see Figure 3) clearly indicates a higher number of 'resit' grades in the first two levels of study (Level $3 \& 4$ ), giving highly 
skewed curves, while the performance in later levels of study approach a bell curve.

This suggests that the first two years of the LL.B. programme, may serve as a 'sieve' filtering out those who are unable to cope with the demands of studying through the distance mode. Figure 1 shows that the print material of courses in the LL.B. programme offer workloads well below the expected level. However, workload here had not included reference material and case studies which form a necessary component of these courses.

It would be useful if future studies could investigate these other areas of study material of the LL.B. programme to find out what effect coping with those areas would have on performance.

Responses from graduands indicate a high success rate of carrying two credits per academic year for the LL.B. programme. It would have been more desirable to look at the total population to ascertain what percentage achieved this goal. Responses from the Science graduands, however, indicate a much lower success rate in carrying two credits. This difficulty may reflect the effects of overloading. The Science students during the period of this study in 1992, needed to complete only four credits with eligibility in two more credits. This requirement may have prompted students to 'drop' selected courses after achieving eligibility. Observed results may reflect this phenomenon. The re-structured programmes that are ongoing now need six credits for completion. Comparison of performance 'then' and 'now' may provide better insight into this issue.

Student perceptions of the workload indicate that a larger percentage of those who study regularly as well as older students appear confident in their ability to carry two credits each academic year. This was clear in the samples for the B.Sc, B.Tech and Diploma in Technology programmes. Students following the LL.B. programme were more apprehensive with no one considering the task 'very easy' or 'easy'. The majority perception seems to be that the workload of 900 study hours per academic year is manageable. The study would have yielded more insights, if perceptions could have been matched 
with actual achievements. This was not possible within the scope of this study.

Studies in the U.K. have shown that a full time student can only devote a maximum of 40 hours per week for study (McKay, 1978: Vos, 1991). In the U.K., the total number of weeks add up to 32 and the total study time to 1200 hours. On this basis, OUSL expectations of completing two credits per academic year seem alarmingly close to that of full time study.

This paper raises many issues for further investigation. It may be necessary to carry out a more stringent assessment of workload of courses and relate them to drop-out rates and performance distribution. Where necessary it should lead to further course evaluation. It may also be desirable to review existing student assessment procedures to clarify whether these have influenced grade distribution patterns. Such studies must be carried out regularly if we are to ensure the effectiveness of distance education programmes.

\section{REFERENCES}

Chambers, E. A. (1989). Student Workload and How to Assess it Teaching and Consultancy Centre, Institute of Educational Technology, internal report, Milton Keynes: The Open University.

Chambers, E. A. (1992). Workload and the quality of student learning, Studies in Higher Education, Vol. 1, No. 2.

Chambers, E. A. (1994). Assessing learner workload. In F. Lockwood (Ed.). Materials Production in Open and Distance Learning. London: Paul Chapman.

Lockwood, F. G., Williams, A. I. \& Roberts, D. W. (1988). Improving teaching at a distance within the University of the South Pacific, International Journal of Educational Development, Vol. 8, No. 3 
McKay, R. (1978). Effectiveness of learning: the place of study. In D.W. Piper (Ed.). The Efficiency and Effectiveness of Teaching in Higher Education, Institute of Education, London: University of London.

Novak, J. D. (1986). A Theory of Education. USA: Cornell: University Press.

Samarawickrema, R. G. (1997). OUSL House Style, Sri Lanka: Open University Press.

Vos, P. (1991). Curriculum control of learning processes in higher education, Proceedings of the 13th International Forum on Higher Education of the European Association for Institutional Research ${ }_{2}$ Edinburgh.

Woodley, A. \& Parlett, M. (1983). Student drop-out, Teaching at a Distance, Vol. 24, Autumn. 